\title{
The Immune Response Is Involved in Atherosclerotic Plaque Calcification: Could the RANKL/RANK/OPG System Be a Marker of Plaque Instability?
}

\author{
Fabrizio Montecucco, Sabine Steffens, and François Mach \\ Division of Cardiology, Foundation for Medical Researches, University Hospital of Geneva, 1211 Geneva, Switzerland \\ Correspondence should be addressed to François Mach, francois.mach@medecine.unige.ch
}

Received 16 August 2007; Accepted 14 October 2007

Recommended by Charles Mackay

\begin{abstract}
Atherogenesis is characterized by an intense inflammatory process, involving immune and vascular cells. These cells play a crucial role in all phases of atherosclerotic plaque formation and complication through cytokine, protease, and prothrombotic factor secretion. The accumulation of inflammatory cells and thus high amounts of soluble mediators are responsible for the evolution of some plaques to instable phenotype which may lead to rupture. One condition strongly associated with plaque rupture is calcification, a physiopathological process orchestrated by several soluble factors, including the receptor activator of nuclear factor $(\mathrm{NF}) \kappa \mathrm{B}$ ligand (RANKL)/receptor activator of nuclear factor (NF) $\kappa \mathrm{B}$ (RANK)/osteoprotegerin (OPG) system. Although some studies showed some interesting correlations with acute ischemic events, at present, more evidences are needed to evaluate the predictive and diagnostic value of serum sRANKL and OPG levels for clinical use. The major limitation is probably the poor specificity of these factors for cardiovascular disease. The identification of tissue-specific isoforms could increase the importance of sRANKL and OPG in predicting calcified plaque rupture and the dramatic ischemic consequences in the brain and the heart.
\end{abstract}

Copyright (C) 2007 Fabrizio Montecucco et al. This is an open access article distributed under the Creative Commons Attribution License, which permits unrestricted use, distribution, and reproduction in any medium, provided the original work is properly cited.

\section{INTRODUCTION}

During the recent years, atherogenesis has been well known as an intense inflammatory systemic process, involving immune and vascular cells [1]. The anatomic structure of atherosclerotic plaques is well known. The atherosclerotic plaque is localized in the arterial intima and contains immune cells ( $\mathrm{T}$ cells, B cells, NK cells, monocyte/ macrophages, mast cells, dendritic cells), foam cells, vascular endothelial cells, and smooth muscle cells [2-5], that are around a core of lipids, extracellular matrix and lipid-rich debris from dead cells [1]. All these cells play a crucial role in all phases of atherosclerotic plaque formation and complication through $\mathrm{T}_{\mathrm{H}}$ 1-type cytokine, protease, and prothrombotic factor secretion [2]. On the other hand, despite these proatherosclerotic activities, these cells are also capable of attenuating the maturation of atherosclerotic plaques, through the production of anti-inflammatory cytokines, such as TGF$\beta$ and IL-10 [6, 7]. In particular, a subpopulation of T cells, called $\mathrm{CD} 4^{+} \mathrm{CD} 25^{+}$regulatory $\mathrm{T}$ cells $\left(\mathrm{T}_{\text {reg }}\right)$, was recently shown to reduce atherosclerosis in $\mathrm{ApoE}^{-/-}$mice $[8,9]$. A fibrous cap of smooth muscle cells and collagen fibres surrounds the complex pro/anti-inflammatory tissue (called lipid core); and an endothelial cell layer divides the plaque from the blood stream [1]. The plasticity of these cells and the great variety of soluble mediators are responsible for the evolution of some plaques to instability, with high risk of fibrous cap disruption and the subsequent acute ischemic and thrombotic events, such as artery occlusion or arterial embolism. One condition strongly associated to plaque rupture is calcification [10-13]. In fact, the degree of calcification promotes the number of interfaces between rigid and distensible portions of the plaque until the point of rupture. This suggests that dystrophic calcification at the thin fibrous cap [14], rather than the histological appearance of fully formed bone with trabeculations of the plaque [15], is related to the increased risk of plaque rupture with the consequent dramatic ischemic events [16]. Monocytes, dendritic cells, and smooth muscle cells are crucial for calcium deposition in the lesion, because of their retained capability to 
differentiate into osteoblast-like cells and osteoclast-like cells [17-22]. These cells, controlled by cytokines and other soluble factors, are the key players of the calcification process.

\section{CURRENT STRATEGIES TO REDUCE PLAQUE CALCIFICATION}

During the last decades, some unstandardized treatments have been proposed to reduce the maturation of the plaque towards calcification. Given the involvement of immune cells, an immunosuppressing pharmacological approach was attempted with some significant results. For instance, in preclinical studies, cyclosporin was found capable of reducing intimal cell proliferation after arterial injury [23]. In addition, clinical studies suggested that sirolimus and statins reduce atherosclerotic complications [24, 25]. Employing a different strategy, researchers focused their attention on molecules capable of reducing atherosclerotic risk factors. Beta blockers and estrogens were found capable of reducing the development of calcification in coronary arteries $[26,27]$. No clear evidences for antiatherosclerotic activities are actually attributed to the ligands for peroxisomeproliferator-activated receptors (PPARs), the nonsteroidal anti-inflammatory drugs (NSAIDs), and bisphosphonates, because there were controversial effects between in vitro and in vivo experiences [28-33]. All these pharmacological molecules were focused on modulating the innate and adaptive immunity to reduce the inflammatory processes, and thus preventing plaque calcification. On the other hand, Price and coworkers also proposed a new therapeutic approach, focused on arterial calcification physiopathology. They performed a treatment with $1 \mathrm{mg}$ /day osteoprotegerin (OPG) for inhibiting artery calcification induced by Warfarin and by vitamin $\mathrm{D}$ in mice and they obtained a dramatic reduction of calcification of arteries [34]. Although the real role of OPG as a cardiovascular risk factor is not well clarified and further studies are needed, the use of OPG could be a very promising therapeutic strategy based on arterial physiopathology. Another approach independent of $\mathrm{CD} 4^{+} \mathrm{T}$ cell activation was recently performed. For instance, $\mathrm{Ldlr}^{-/-}$ mice vaccinated with malondialdehyde-modified LDL; and HSP60 demonstrated some encouraging preliminary results $[35,36]$. Intriguingly, these interventions strongly support the importance of humoral immunity in atherosclerotic processes. The modulation of both innate and adaptive immunity may be a useful strategy to reduce the development of atherosclerotic plaque calcification. The development of new therapeutic approaches is needed because when established, arterial calcifications are irreversible [37] and, despite controversies, only the surgical treatment remains [38]. For all these reasons, new therapies capable of reducing established and developing calcification of the plaque need to be developed to reduce acute ischemic cardiovascular events, independently of traditional risk factors [39-43]. The present review is focused on identifying molecular mechanisms and serological markers to better characterize the cardiovascular risk and possible targets for future therapies against arterial calcification and the consequent plaque rupture.

\section{MOLECULAR MECHANISMS OF ARTERIAL CALCIFICATION}

Although previously considered as a passive precipitation, recent work suggests that calcium mineral deposition in atherosclerotic plaques is the result of intra-arterial processes of osteogenesis [10]. Despite considerable confusion, in 2004 Doherty et al. had identified two different types of arterial calcification, localized in the media or the intima, respectively [44]. Medial and intimal calcifications are different entities that are not necessarily separated from each other. In fact, medial calcification occurs independently of atherosclerosis [45], and is observed with high frequency in Monckeberg's sclerosis [46], hypervitaminosis D [47], end-stage renal failure disease (ESRD) $[48,49]$, and diabetes mellitus $[50,51]$. Although the precise mechanism of medial calcification is not clear, at least for ESRD, an association between arterial calcification and increased serum phosphorus and increased ion product $\left[\mathrm{Ca}^{2+} \times \mathrm{PO}_{4}{ }^{-3}\right]$ was shown [52]. In diabetes mellitus, different hypotheses for medial calcification formation were formulated. For instance, Edmonds suggested a possible involvement of stiffening of arterial tone and endothelial dysfunction [53]. However, much remains to be investigated about medial arterial calcification, such as a possible association with the cardiovascular risk $[54,55]$.

On the other hand, intimal calcification was observed almost exclusively in atherosclerotic plaques [10], and it occurs in two distinct patterns (punctate or diffuse), with still unclear implications [44]. So far, several molecular mechanisms of plaque calcification have been identified, with many similarities to physiopathological processes of bone formation [56] and resorption [57]. Intimal arterial calcification might be secondary to an imbalance between these two opposing processes, with the inhibition of osteoclast-like (OCL) cell mineral resorption and the increase of osteoblast-like (OBL) cell mineral deposition [58]. In the following, we will discuss three different models of plaque calcification that have been proposed by Doherty and colleagues, with complementary molecular mechanisms, which might be involved [59].

\subsection{The "active model" of arterial calcification}

In 1993, Bostrom et al. showed the presence of pluripotent arterial cells, called calcifying vascular cells (CVCs), which are immunologically distinct from the other arterial cells [60]. These cells colocalized in atherosclerotic plaques with bone-related proteins and transcriptional factors, such as BMP-2 and Cbfa1 [60, 61]. Furthermore, they were found capable of forming in vitro mineralized structures $[62,63]$. These data were confirmed by other groups, which extended the active model of bone matrix formation also to other arterial cell types, such as smooth muscle cells [64-66]. The name "active model" is derived from the bone formation activity of these cells, also called OBL cells. The validity of the present model was also confirmed by in vivo experiences showing that both human and animal artery mineralization processes are very similar to that observed in bone [67-69]. 


\subsection{The "passive physicochemical model" of arterial calcification}

This model was proposed by Gijsbers et al. [70] and Schinke and Karsenty [71] and is based on the concept that calcium and phosphate ions are in a metastable state when they are near the point of precipitation in solid phase within biological fluids. Vermeer showed that several proteins, which chelate calcium cations, inhibited mineral salt deposition in arteries. These proteins (mainly homeostatic clotting factors and osteocalcin) were found to contain glutamine residues carboxylated at the $\gamma$-position gamma-carboxyglutamic acid (Gla) residues, and thus were called Gla proteins [72]. In accordance with this model, atherosclerotic plaque calcification is due to a deficient chemical $\gamma$-carboxylation of Gla proteins. This "passive" model is mainly supported by two several independent findings. First, the enzyme $\boldsymbol{\gamma}$-carboxylase was found less active in atherosclerotic rather than in normal arteries in both humans and animals [13, 73]. This may be due to a deficiency of the two cofactors (two isoforms of vitamin $\mathrm{K}$, named phylloquinone and menaquinone), needed for the chemical reaction [74]. Secondly, mice deficient for matrix gamma-carboxyglutamic acid (Gla) protein (MGP) showed a massive arterial calcification [75].

On the other hand, other studies raised several doubts on the real relevance of the passive model of arterial calcification. For instance, in Keutel syndrome, a human disease characterized by a nonfunctional MGP gene, patients do not develop a massive arterial calcification [73]. In addition, MGP knockout mice and rats develop medial rather than intimal calcification, which characterizes atherosclerosis [75]. Therefore, a combined role of MGP deficiency with other factors has been suggested. Moreover, the cysteine protease inhibitor AHSG [76], apoptotic bodies [77], and lipids [78] were found to be important modulatory factors of atherosclerotic intimal calcification. To summarize, current evidence suggests that the "passive" model of calcification appears to be relevant mainly in medial calcification, a histological entity not clearly related to atherosclerosis.

\subsection{The arterial OCL model}

We have previously described that bone remodelling results from the balance between formation (osteoblasts) and degradation (osteoclasts). While the "active model" highlights the importance of OBL cells, the "arterial OCL model" proposes that arterial calcification is due to a lack of activity of OCL cells. Several molecular factors influence OCL survival, differentiation, and function. Macrophage-colony stimulating factor (M-CSF), a cytokine, and growth factor for mononuclear phagocytic cells (MPCs) is crucial in survival and differentiation of osteoclast progenitors $[57,79]$. This role is strongly supported by independent evidences, showing that the lack of M-CSF alone was sufficient to reduce the number of osteoclasts and induce osteopetrosis [80-82]. In addition, despite a significant reduction of atherosclerotic lesion formation, mice deficient for both M-CSF and apoliprotein (apo) E-developed plaque calcification [83]. These data highlight the dual role of M-CSF in atherosclerosis: the promo- tion of atherogenesis (plaque formation) and the inhibition of plaque calcification (plaque complication).

On the other hand, the receptor activator of nuclear factor $(\mathrm{NF}) \kappa \mathrm{B}$ ligand (RANKL), which is also called tumor necrosis factor- [TNF-] related activation-induced cytokine (TRANCE) or osteoprotegerin ligand (OPGL) [84], is also necessary and sufficient for the generation and function of OCL cells in the plaque (Figure 1). RANKL, which is expressed in unstable atherosclerotic plaques [85-87], is capable of modulating different cell-type activities (mainly monocyte-derived osteoclast precursors, $\mathrm{T}$ cells, B cells, and dendritic cells) $[88,89]$ through its transmembrane receptor RANK. After the binding with RANK, several intracellular signal transduction pathways are activated, with crucial role for mitogen-activated protein kinases (MAPKs) and $(\mathrm{NF}) \kappa \mathrm{B}[90,91]$. Taking into the account these premises, RANKL appears as an anticalcifying molecule, and probably capable of reducing the plaque vulnerability. Some of these findings were not confirmed by Sandberg and colleagues [87], showing surprisingly that RANKL induces plaque instability in humans by inducing MCP-1 and matrix metalloproteinase (MMP) production [87]. Thus, the exact role of RANKL in plaque dystrophic calcification remains unclear. In fact, in absence of the RANKL neutralizing agent OPG, the decoy receptor of RANKL, mice not only developed osteoporosis (bone loss), but also arterial calcification [92]. There are at least two explanations suggesting a different role of RANKL between human and mice. First, although expressed in human arteries, RANKL, and RANK are not expressed in normal mouse arteries, but only in calcified plaque [93]. This suggests that the calcification process itself might upregulate RANK and RANKL expression and signalling. In this case, RANKL-induced OCL anticalcification activity is secondary to the establishment of a consolidated calcification, without involvement in plaque formation and maturation, at least in mice. Second, RANKL signalling can also promote mineral deposition in mouse plaques. This interesting hypothesis is sustained by Lin et al., showing osteoblast proliferation in murine calvarial organ culture [94]. On the contrary, evidences showed RANKL and OPG presence and activity in early and advanced atherosclerotic lesions in humans $[95,96]$. The soluble form of RANKL and serum OPG detected in human blood stream (mainly released from endothelial cells) are both under investigation as possible clinical biomarkers of several bone-related diseases, including atherosclerosis [97, 98]. Therefore, even though the full mechanism of bone resorption is still not clarified, the "OCL model" has to be considered as directly involved in intimal plaque calcification through the active inhibition of calcification and the degradation of existing mineral deposits.

\section{MOLECULAR FACTORS INVOLVED IN ATHEROSCLEROTIC ARTERIAL CALCIFICATION}

Although several studies on arterial calcification have been performed, the molecular mechanisms influencing bone metabolism are still unclear. Bone remodelling is a process common to various diseases, often coexisting. The real 


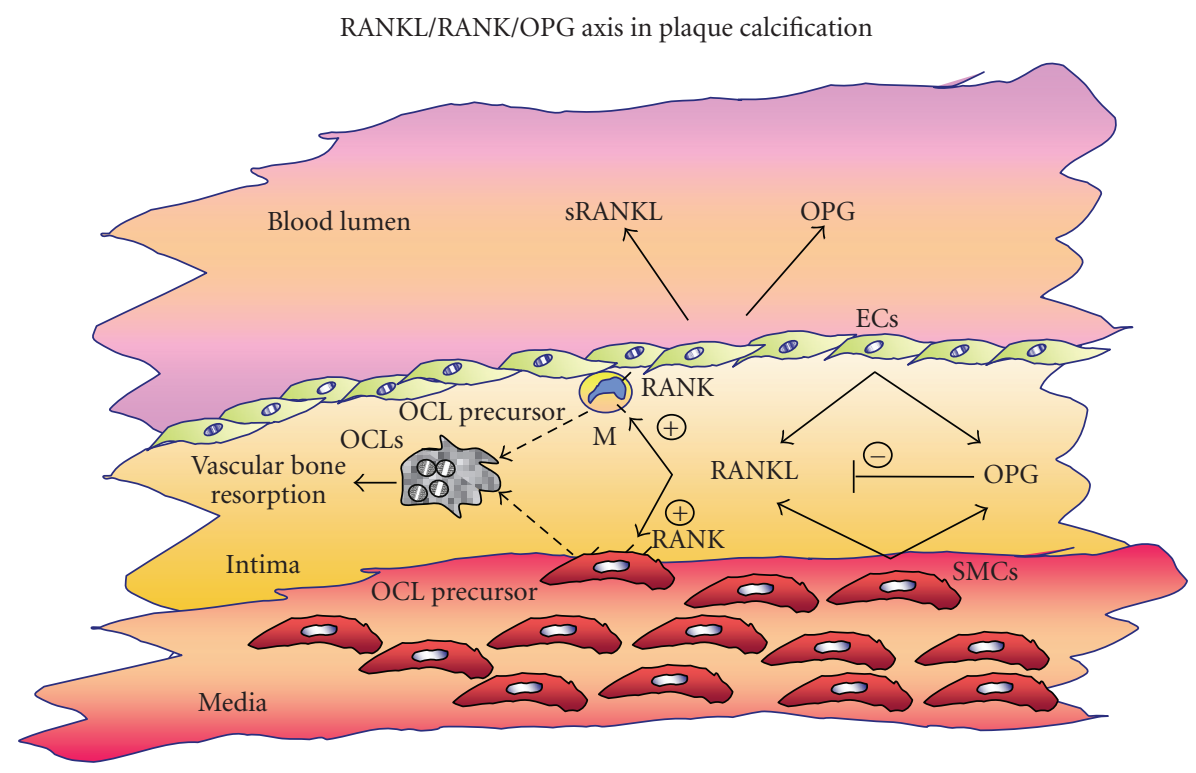

FIGURE 1: Schematic diagram of potential OCL differentiation in the plaque. Soluble RANKL (sRANKL) and OPG are secreted in the atherosclerotic plaque and in the blood stream mainly by smooth muscle cells (SMCs) and endothelial cells (ECs). sRANKL promotes OCL precursor (mainly monocytes/macrophages (M), dendritic cells, and SMCs) differentiation into OCL cells (as indicated by dotted arrows). OPG neutralizes the action of RANKL. The balance between these two soluble molecules regulates the bone resorption in calcified plaques, which is correlated to plaque rupture.

difficulty is to define a biomarker specific only for the cardiovascular risk of plaque rupture and not influenced by osteoporosis, renal failure, or other bone-related diseases. For these reasons, several parameters altered or involved in bone metabolism have been studied. Investigators started with parathyroid hormone $(\mathrm{PTH})$ and vitamin $\mathrm{D}$, which are the principal factors for bone homeostasis. Discordant results were obtained [99-101] and actually no clear correlation between PTH, vitamin $\mathrm{D}$, and vascular calcification were observed. On the other hand, given the low incidence of coronary heart disease (CHD) in premenopausal women [102], estrogens were investigated. Substantial evidence showed that estrogens have an antiatherogenic effect, mainly through lipid-lowering [103] and endothelial nitric oxide synthase (eNOS) activation [104]. A direct casual relationship with estrogens and arterial calcification has been shown recently [27], even though further evidences are needed. Lipid metabolism and leptin were studied as possible markers of plaque calcification, but no direct correlations were identified [105]. Other markers were analysed by Doherty et al., but they require further studies to better elucidate their potential importance [44]. Among these markers, the RANKL/RANK/OPG system appears as the most promising for an application in the near future.

\section{COULD THE RANKL/RANK/OPG SYSTEM BE CONSIDERED AS A SEROLOGICAL MARKER FOR PLAQUE RUPTURE IN THE FUTURE?}

As previously described, there is strong evidence for an implication of the RANKL/RANK/OPG network in vascular calcification. However, atherosclerotic arterial calcification shares the activation of this system with other pathologies, such as rheumatoid arthritis, osteoporosis, cancer metastasis $[106,107]$, and other vascular diseases, such as diabetic macroangiopathy, aortic aneurism, and heart failure [108]. Several studies indicate that the RANKL/RANK/OPG axis is not specific for plaque calcification and destabilization. Nevertheless, OPG and sRANKL serum levels have been proposed as biomarkers of vascular risk and prognosis. The serum levels of OPG were measured in patients with cerebrovascular disease, stable angina, and coronary artery disease (CAD), and showed interesting correlations. In particular, OPG levels were independently associated with cardiovascular mortality, but not bone mineral density in patients suffering from cerebrovascular diseases [109]. Furthermore, OPG is correlated with significant coronary artery narrowing [110]. Interestingly, osteoprotegerin gene polymorphisms were shown in coronary artery disease in Caucasian men [111]. Finally, serum OPG levels were associated to the severity of CAD [112]. However, although further clinical studies are needed to confirm that serum OPG levels might help to evaluate the prognosis of vascular disease. Serum levels of free- (not complexed to OPG) soluble RANKL (sRANKL) were also found altered in CAD patients. In particular, they were significantly lower in patients with CAD, without reporting a correlation to the severity of the disease [113]. These findings were also confirmed by Jono et al. [112] and Sandberg et al. [87], demonstrating the increase of levels of RANKL expression in T cells during acute coronary syndrome [87]. Although OPG and free-soluble RANKL might be considered as a promising marker of cardiovascular risk, their application might be limited by poor tissue specificity. For this reason, the identification of tissue-specific isoforms of OPG and RANKL could contribute to highly increase future diagnostic and prognostic significances. 


\section{CONCLUSIONS}

The present review shows that plaque calcification represents a crucial step for plaque destabilization and rupture. Some serological markers are needed to be validated for better defining cardiovascular risk and prognosis of acute ischemic complications, secondary to plaque rupture. Although not selective only for arterial calcification, the RANKL/RANK/OPG axis could be a promising risk marker and target for future therapies. In this context, experimental data have provided the first evidence for the therapeutic use of OPG as possible pharmacologic agent for reducing arterial calcification [34]. On the contrary, human data suggested the direct relationship between increased OPG serum levels and plaque destabilization. This may imply that elevated OPG levels could be compensatory rather than causational in atherosclerotic calcification. Therefore, further clinical investigations with large number of patients are required to better clarify the role of serum sRANKL and OPG in plaque physiopathology.

\section{ACKNOWLEDGMENTS}

This work was supported by grants from the Swiss National Science Foundation to Dr. Mach (\#320080-105836) and Dr. Steffens (\#310000-116324). The authors belong to the European Vascular Genomics Network (http://www.evgn.org), a Network of Excellence supported by the European Community.

\section{REFERENCES}

[1] G. K. Hansson and P. Libby, "The immune response in atherosclerosis: a double-edged sword," Nature Reviews Immunology, vol. 6, no. 7, pp. 508-519, 2006.

[2] G. K. Hansson, P. Libby, U. Schönbeck, and Z.-Q. Yan, "Innate and adaptive immunity in the pathogenesis of atherosclerosis," Circulation Research, vol. 91, no. 4, pp. 281291, 2002.

[3] E. Faure, L. Thomas, H. Xu, A. E. Medvedev, O. Equils, and M. Arditi, "Bacterial lipopolysaccharide and IFN- $\gamma$ induce toll-like receptor 2 and toll-like receptor 4 expression in human endothelial cells: role of NF- $\kappa \mathrm{B}$ activation," Journal of Immunology, vol. 166, no. 3, pp. 2018-2024, 2001.

[4] S. Akira, "Toll-like receptors and innate immunity," Advances in Immunology, vol. 78, pp. 1-56, 2001.

[5] J. S. Pober, T. Collins, M. A. Gimbrone Jr., P. Libby, and C. S. Reiss, "Inducible expression of class II major histocompatibility complex antigens and the immunogenicity of vascular endothelium," Transplantation, vol. 41, no. 2, pp. 144-146, 1986.

[6] L. J. Pinderski Oslund, C. C. Hedrick, T. Olvera, et al., "Interleukin-10 blocks atherosclerotic events in vitro and in vivo," Arteriosclerosis, Thrombosis, and Vascular Biology, vol. 19, no. 12, pp. 2847-2853, 1999.

[7] Z. Mallat, A. Gojova, C. Marchiol-Fournigault, et al., "Inhibition of transforming growth factor- $\beta$ signaling accelerates atherosclerosis and induces an unstable plaque phenotype in mice," Circulation Research, vol. 89, no. 10, pp. 930-934, 2001.
[8] H. Ait-Oufella, B. L. Salomon, S. Potteaux, et al., "Natural regulatory $\mathrm{T}$ cells control the development of atherosclerosis in mice," Nature Medicine, vol. 12, no. 2, pp. 178-180, 2006.

[9] Z. Mallat, H. Ait-Oufella, and A. Tedgui, "Regulatory Tcell immunity in atherosclerosis," Trends in Cardiovascular Medicine, vol. 17, no. 4, pp. 113-118, 2007.

[10] H. C. Stary, "Natural history of calcium deposits in atherosclerosis progression and regression," Zeitschrift für Kardiologie, vol. 89, supplement 2, pp. 28-35, 2000.

[11] R. C. Detrano, T. M. Doherty, M. J. Davies, and H. C. Stary, "Predicting coronary events with coronary calcium: pathophysiologic and clinical problems," Current Problems in Cardiology, vol. 25, no. 6, pp. 374-402, 2000.

[12] P. G. O’Malley, A. J. Taylor, J. L. Jackson, T. M. Doherty, and R. C. Detrano, "Prognostic value of coronary electron-beam computed tomography for coronary heart disease events in asymptomatic populations," The American Journal of Cardiology, vol. 85, no. 8, pp. 945-948, 2000.

[13] T. M. Doherty and R. C. Detrano, "Coronary arterial calcification as an active process: a new perspective on an old problem," Calcified Tissue International, vol. 54, no. 3, pp. 224230, 1994.

[14] Z.-Y. Li, S. Howarth, T. Tang, M. Graves, J. U-King-Im, and J. H. Gillard, "Does calcium deposition play a role in the stability of atheroma? Location may be the key," Cerebrovascular Diseases, vol. 24, no. 5, pp. 452-459, 2007.

[15] M. Jeziorska, C. McCollum, and D. E. Woolley, "Observations on bone formation and remodelling in advanced atherosclerotic lesions of human carotid arteries," Virchows Archiv, vol. 433, no. 6, pp. 559-565, 1998.

[16] W. G. Beadenkopf, A. S. Daoud, and B. M. Love, "Calcification in the coronary arteries and its relationship to arteriosclerosis and myocardial infarction," American Journal of Roentgenology, vol. 92, pp. 865-871, 1964.

[17] S. Jono, M. D. McKee, C. E. Murry, et al., "Phosphate regulation of vascular smooth muscle cell calcification," Circulation Research, vol. 87, no. 7, pp. E10-E17, 2000.

[18] A. E. Canfield, M. J. Doherty, V. Kelly, et al., "Matrix Gla protein is differentially expressed during the deposition of a calcified matrix by vascular pericytes," FEBS Letters, vol. 487, no. 2, pp. 267-271, 2000.

[19] K. Mori, A. Shioi, S. Jono, Y. Nishizawa, and H. Morii, "Dexamethasone enhances in vitro vascular calcification by promoting osteoblastic differentiation of vascular smooth muscle cells," Arteriosclerosis, Thrombosis, and Vascular Biology, vol. 19, no. 9, pp. 2112-2118, 1999.

[20] K. E. Watson, K. Boström, R. Ravindranath, T. Lam, B. Norton, and L. L. Demer, "TGF- $\beta 1$ and 25-hydroxycholesterol stimulate osteoblast-like vascular cells to calcify," Journal of Clinical Investigation, vol. 93, no. 5, pp. 2106-2113, 1994.

[21] K.-W. Kim, M.-L. Cho, S.-H. Lee, et al., "Human rheumatoid synovial fibroblasts promote osteoclastogenic activity by activating RANKL via TLR-2 and TLR-4 activation," Immunology Letters, vol. 110, no. 1, pp. 54-64, 2007.

[22] M. S. Kim, C. J. Day, and N. A. Morrison, "MCP-1 is induced by receptor activator of nuclear factor $-\kappa \mathrm{B}$ ligand, promotes human osteoclast fusion, and rescues granulocyte macrophage colony-stimulating factor suppression of osteoclast formation," Journal of Biological Chemistry, vol. 280, no. 16, pp. 16163-16169, 2005.

[23] L. Jonasson, J. Holm, and G. K. Hansson, "Cyclosporin A inhibits smooth muscle proliferation in the vascular response to injury," Proceedings of the National Academy of Sciences of 
the United States of America, vol. 85, no. 7, pp. 2303-2306, 1988.

[24] M. Poon, J. J. Badimon, and V. Fuster, "Overcoming restenosis with sirolimus: from alphabet soup to clinical reality," The Lancet, vol. 359, no. 9306, pp. 619-622, 2002.

[25] "Randomised trial of cholesterol lowering in 4444 patients with coronary heart disease: the Scandinavian Simvastatin Survival Study (4S)," The Lancet, vol. 344, no. 8934, pp. 1383 1389, 1994.

[26] S. J. Nicholls, E. M. Tuzcu, K. Wolski, et al., "Coronary artery calcification and changes in atheroma burden in response to established medical therapies," Journal of the American College of Cardiology, vol. 49, no. 2, pp. 263-270, 2007.

[27] J. E. Manson, M. A. Allison, J. E. Rossouw, et al., "Estrogen therapy and coronary-artery calcification," The New England Journal of Medicine, vol. 356, no. 25, pp. 2591-2602, 2007.

[28] N. Marx, B. Kehrle, K. Kohlhammer, et al., "PPAR activators as antiinflammatory mediators in human $\mathrm{T}$ lymphocytes: implications for atherosclerosis and transplantationassociated arteriosclerosis," Circulation Research, vol. 90, no. 6, pp. 703-710, 2002.

[29] B. M. Psaty and C. D. Furberg, "The record on Rosiglitazone and the risk of myocardial infarction," The New England Journal of Medicine, vol. 357, no. 1, pp. 67-69, 2007.

[30] G. A. FitzGerald, "Coxibs and cardiovascular disease," The New England Journal of Medicine, vol. 351, no. 17, pp. 17091711, 2004.

[31] S. D. Solomon, J. J. V. McMurray, M. A. Pfeffer, et al., "Cardiovascular risk associated with celecoxib in a clinical trial for colorectal adenoma prevention," The New England Journal of Medicine, vol. 352, no. 11, pp. 1071-1080, 2005.

[32] P. A. Price, S. A. Faus, and M. K. Williamson, "Bisphosphonates alendronate and ibandronate inhibit artery calcification at doses comparable to those that inhibit bone resorption," Arteriosclerosis, Thrombosis, and Vascular Biology, vol. 21, no. 5, pp. 817-824, 2001.

[33] M. Shimshi, E. Abe, E. A. Fisher, M. Zaidi, and J. T. Fallon, "Bisphosphonates induce inflammation and rupture of atherosclerotic plaques in apolipoprotein-E null mice," Biochemical and Biophysical Research Communications, vol. 328, no. 3, pp. 790-793, 2005.

[34] P. A. Price, H. H. June, J. R. Buckley, and M. K. Williamson, "Osteoprotegerin inhibits artery calcification induced by warfarin and by vitamin D," Arteriosclerosis, Thrombosis, and Vascular Biology, vol. 21, no. 10, pp. 1610-1616, 2001.

[35] S. Freigang, S. Hörkkö, E. Miller, J. L. Witztum, and W. Palinski, "Immunization of LDL receptor-deficient mice with homologous malondialdehyde-modified and native LDL reduces progression of atherosclerosis by mechanisms other than induction of high titers of antibodies to oxidative neoepitopes," Arteriosclerosis, Thrombosis, and Vascular Biology, vol. 18, no. 12, pp. 1972-1982, 1998.

[36] D. Harats, N. Yacov, B. Gilburd, Y. Shoenfeld, and J. George, "Oral tolerance with heat shock protein 65 attenuates $m y$ cobacterium tuberculosis-induced and high-fat-diet-driven atherosclerotic lesions," Journal of the American College of Cardiology, vol. 40, no. 7, pp. 1333-1338, 2002.

[37] A. Bas, I. Lopez, J. Perez, M. Rodriguez, and E. AguileraTejero, "Reversibility of calcitriol-induced medial artery calcification in rats with intact renal function," Journal of Bone and Mineral Research, vol. 21, no. 3, pp. 484-490, 2006.

[38] Y. Ikari, "Treatment for coronary artery calcification," Clinical Calcium, vol. 17, no. 3, pp. 381-385, 2007.
[39] M. J. Budoff, S. Achenbach, R. S. Blumenthal, et al., "Assessment of coronary artery disease by cardiac computed tomography: a scientific statement from the American Heart Association Committee on Cardiovascular Imaging and Intervention, Council on Cardiovascular Radiology and Intervention, and Committee on Cardiac Imaging, Council on Clinical Cardiology," Circulation, vol. 114, no. 16, pp. 1761-1791, 2006.

[40] Y. Arad, L. A. Spadaro, K. Goodman, D. Newstein, and A. D. Guerci, "Prediction of coronary events with electron beam computed tomography," Journal of the American College of Cardiology, vol. 36, no. 4, pp. 1253-1260, 2000.

[41] P. Raggi, L. J. Shaw, D. S. Berman, and T. Q. Callister, "Prognostic value of coronary artery calcium screening in subjects with and without diabetes," Journal of the American College of Cardiology, vol. 43, no. 9, pp. 1663-1669, 2004.

[42] P. Greenland, L. LaBree, S. P. Azen, T. M. Doherty, and R. C. Detrano, "Coronary artery calcium score combined with framingham score for risk prediction in asymptomatic individuals," Journal of the American Medical Association, vol. 291, no. 2, pp. 210-215, 2004.

[43] P. Greenland, L. LaBree, S. P. Azen, T. M. Doherty, and R. C. Detrano, "Erratum: coronary artery calcium score combined with framingham score for risk prediction in asymptomatic individuals," Journal of the American Medical Association, vol. 291, no. 5, p. 563, 2004.

[44] T. M. Doherty, L. A. Fitzpatrick, D. Inoue, et al., "Molecular, endocrine, and genetic mechanisms of arterial calcification," Endocrine Reviews, vol. 25, no. 4, pp. 629-672, 2004.

[45] D. Proudfoot and C. M. Shanahan, "Biology of calcification in vascular cells: intima versus media," Herz, vol. 26, no. 4, pp. 245-251, 2001.

[46] J. G. Mönckeberg, "Über die reine Mediaverkalkung der Extremitätenarterien und ihr Verhalten zur Arteriosklerose," Virchows Archiv, vol. 171, no. 1, pp. 141-167, 1903.

[47] N. P. Mallick and G. M. Berlyne, "Arterial calcification after vitamin-D therapy in hyperphosphatemic renal failure," The Lancet, vol. 292, no. 7582, pp. 1316-1320, 1968.

[48] R. N. Foley, P. S. Parfrey, and M. J. Sarnak, "Epidemiology of cardiovascular disease in chronic renal disease," Journal of the American Society of Nephrology, vol. 9, pp. S16-S23, 1998.

[49] S. M. Moe, K. D. O’Neill, D. Duan, et al., "Medial artery calcification in ESRD patients is associated with deposition of bone matrix proteins," Kidney International, vol. 61, no. 2, pp. 638-647, 2002.

[50] L. Morrison and I. K. Bogan, "Calcification of the vessels in diabetes," Journal of the American Medical Association, vol. 92, pp. 1424-1426, 1929.

[51] E. Chantelau, K. M. Lee, and R. Jungblut, "Distal arterial occlusive disease in diabetes is related to medial arterial calcification," Experimental and Clinical Endocrinology and Diabetes, vol. 105, supplement 2, pp. 11-13, 1997.

[52] W. G. Goodman, J. Goldin, B. D. Kuizon, et al., "Coronaryartery calcification in young adults with end-stage renal disease who are undergoing dialysis," The New England Journal of Medicine, vol. 342, no. 20, pp. 1478-1483, 2000.

[53] M. E. Edmonds, "Medial arterial calcification and diabetes mellitus," Zeitschrift für Kardiologie, vol. 89, supplement 2, pp. 101-104, 2000.

[54] L. Niskanen, O. Siitonen, M. Suhonen, and M. I. Uusitupa, "Medial artery calcification predicts cardiovascular mortality in patients with NIDDM," Diabetes Care, vol. 17, no. 11, pp. 1252-1256, 1994. 
[55] R. E. Maser, S. K. Wolfson Jr., D. Ellis, et al., "Cardiovascular disease and arterial calcification in insulin-dependent diabetes mellitus: interrelations and risk factor profiles. Pittsburgh Epidemiology of Diabetes Complications Study-V," Arteriosclerosis and Thrombosis, vol. 11, no. 4, pp. 958-965, 1991.

[56] P. Ducy, T. Schinke, and G. Karsenty, "The osteoblast: a sophisticated fibroblast under central surveillance," Science, vol. 289 , no. 5484 , pp. 1501-1504, 2000.

[57] S. L. Teitelbaum, "Bone resorption by osteoclasts," Science, vol. 289 , no. 5484 , pp. 1504-1508, 2000.

[58] T. M. Doherty, H. Uzui, L. A. Fitzpatrick, et al., "Rationale for the role of osteoclast-like cells in arterial calcification," The FASEB Journal, vol. 16, no. 6, pp. 577-582, 2002.

[59] T. M. Doherty, K. Asotra, L. A. Fitzpatrick, et al., "Calcification in atherosclerosis: bone biology and chronic inflammation at the arterial crossroads," Proceedings of the National Academy of Sciences of the United States of America, vol. 100, no. 20, pp. 11201-11206, 2003.

[60] K. Boström, K. E. Watson, S. Horn, C. Wortham, I. M. Herman, and L. L. Demer, "Bone morphogenetic protein expression in human atherosclerotic lesions," Journal of Clinical Investigation, vol. 91, no. 4, pp. 1800-1809, 1993.

[61] M. A. Engelse, J. M. Neele, A. L. J. J. Bronckers, H. Pannekoek, and C. J. M. de Vries, "Vascular calcification: expression patterns of the osteoblast-specific gene core binding factor $\alpha-1$ and the protective factor matrix Gla protein in human atherogenesis," Cardiovascular Research, vol. 52, no. 2, pp. 281-289, 2001.

[62] K. E. Watson, K. Boström, R. Ravindranath, T. Lam, B. Norton, and L. L. Demer, "TGF- $\beta 1$ and 25-hydroxycholesterol stimulate osteoblast-like vascular cells to calcify," Journal of Clinical Investigation, vol. 93, no. 5, pp. 2106-2113, 1994.

[63] M. Balica, K. Boström, V. Shin, K. Tillisch, and L. L. Demer, "Calcifying subpopulation of bovine aortic smooth muscle cells is responsive to $17 \beta$-estradiol," Circulation, vol. 95, no. 7, pp. 1954-1960, 1997.

[64] A. Shioi, M. Katagi, Y. Okuno, et al., "Induction of bone-type alkaline phosphatase in human vascular smooth muscle cells: roles of tumor necrosis factor- $\alpha$ and oncostatin $M$ derived from macrophages," Circulation Research, vol. 91, no. 1, pp. 9-16, 2002.

[65] T. Wada, M. D. McKee, S. Steitz, and C. M. Giachelli, "Calcification of vascular smooth muscle cell cultures: inhibition by osteopontin," Circulation Research, vol. 84, no. 2, pp. 166 $178,1999$.

[66] D. Proudfoot, J. N. Skepper, C. M. Shanahan, and P. L. Weissberg, "Calcification of human vascular cells in vitro is correlated with high levels of matrix Gla protein and low levels of osteopontin expression," Arteriosclerosis, Thrombosis, and Vascular Biology, vol. 18, no. 3, pp. 379-388, 1998.

[67] J.-H. Qiao, R. B. Mertens, M. C. Fishbein, and S. A. Geller, "Cartilaginous metaplasia in calcified diabetic peripheral vascular disease: morphologic evidence of enchondral ossification," Human Pathology, vol. 34, no. 4, pp. 402-407, 2003.

[68] L. A. Fitzpatrick, R. T. Turner, and E. R. Ritman, "Endochondral bone formation in the heart: a possible mechanism of coronary calcification," Endocrinology, vol. 144, no. 6, pp. 2214-2219, 2003.

[69] F. Bea, E. Blessing, B. Bennett, M. Levitz, E. P. Wallace, and M. E. Rosenfeld, "Simvastatin promotes atherosclerotic plaque stability in ApoE-deficient mice independently of lipid lowering," Arteriosclerosis, Thrombosis, and Vascular Biology, vol. 22, no. 11, pp. 1832-1837, 2002.

[70] B. L. Gijsbers, L. J. van Haarlem, B. A. Soute, R. H. Ebberink, and C. Vermeer, "Characterization of a Gla-containing protein from calcified human atherosclerotic plaques," Arteriosclerosis, vol. 10, no. 6, pp. 991-995, 1990.

[71] T. Schinke and G. Karsenty, "Vascular calcification-a passive process in need of inhibitors," Nephrology Dialysis Transplantation, vol. 15, no. 9, pp. 1272-1274, 2000.

[72] C. M. Shanahan, D. Proudfoot, A. Farzaneh-Far, and P. L. Weissberg, "The role of Gla proteins in vascular calcification," Critical Reviews in Eukaryotic Gene Expression, vol. 8, no. 3-4, pp. 357-375, 1998.

[73] P. B. Munroe, R. O. Olgunturk, J.-P. Fryns, et al., "Mutations in the gene encoding the human matrix Gla protein cause Keutel syndrome," Nature Genetics, vol. 21, no. 1, pp. 142$144,1999$.

[74] H. M. H. Spronk, B. A. M. Soute, L. J. Schurgers, H. H. W. Thijssen, J. G. R. De Mey, and C. Vermeer, "Tissue-specific utilization of menaquinone-4 results in the prevention of arterial calcification in warfarin-treated rats," Journal of Vascular Research, vol. 40, no. 6, pp. 531-537, 2003.

[75] G. Luo, P. Ducy, M. D. McKee, et al., "Spontaneous calcification of arteries and cartilage in mice lacking matrix Gla protien," Nature, vol. 386, no. 6620, pp. 78-81, 1997.

[76] T. Schinke, C. Amendt, A. Trindl, O. Pöschke, W. MüllerEsterl, and W. Jahnen-Dechent, "The serum protein $\alpha 2-\mathrm{HS}$ glycoprotein/fetuin inhibits apatite formation in vitro and in mineralizing calvaria cells. A possible role in mineralization and calcium homeostasis," Journal of Biological Chemistry, vol. 271, no. 34, pp. 20789-20796, 1996.

[77] D. Proudfoot, J. N. Skepper, L. Hegyi, A. Farzaneh-Far, C. M. Shanahan, and P. L. Weissberg, "The role of apoptosis in the initiation of vascular calcification," Zeitschrift für Kardiologie, vol. 90, supplement 3, pp. 43-46, 2001.

[78] D. Skrtic and E. D. Eanes, "Membrane-mediated precipitation of calcium phosphate in model of liposomes with matrix vesicle-like lipid composition," Bone and Mineral, vol. 16, no. 2, pp. 109-119, 1992.

[79] T. Suda, K. Kobayashi, E. Jimi, N. Udagawa, and N. Takahashi, "The molecular basis of osteoclast differentiation and activation," Novartis Foundation Symposium, vol. 232, pp. 235-247, 2001.

[80] E. R. Stanley, K. L. Berg, D. B. Einstein, et al., "Biology and action of colony-stimulating factor-1," Molecular Reproduction and Development, vol. 46, no. 1, pp. 4-10, 1997.

[81] W. Wiktor-Jedrzejczak, A. Bartocci, A. W. Ferrante Jr., et al., "Total absence of colony-stimulating factor 1 in the macrophage-deficient osteopetrotic (op/op) mouse," Proceedings of the National Academy of Sciences of the United States of America, vol. 87, no. 12, pp. 4828-4832, 1990.

[82] W. Wiktor-Jedrzejczak, A. Bartocci, A. W. Ferrante Jr., et al., "Correction: total absence of colony-stimulating factor 1 in the macrophage-deficient osteopetrotic (op/op) mouse," Proceedings of the National Academy of Sciences of the United States of America, vol. 88, no. 13, pp. 5937-5941, 1991.

[83] J.-H. Qiao, J. Tripathi, N. K. Mishra, et al., "Role of macrophage colony-stimulating factor in atherosclerosis: studies of osteopetrotic mice," American Journal of Pathology, vol. 150, no. 5, pp. 1687-1699, 1997.

[84] D. L. Lacey, E. Timms, H.-L. Tan, et al., "Osteoprotegerin ligand is a cytokine that regulates osteoclast differentiation and activation," Cell, vol. 93, no. 2, pp. 165-176, 1998. 
[85] Y. Tintut and L. Demer, "Role of osteoprotegerin and its ligands and competing receptors in atherosclerotic calcification," Journal of Investigative Medicine, vol. 54, no. 7, pp. 395401, 2006.

[86] B. J. Bennett, M. Scatena, E. A. Kirk, et al., "Osteoprotegerin inactivation accelerates advanced atherosclerotic lesion progression and calcification in older ApoE-/- mice," Arteriosclerosis, Thrombosis, and Vascular Biology, vol. 26, no. 9, pp. 2117-2124, 2006.

[87] W. J. Sandberg, A. Yndestad, E. Øie, et al., "Enhanced T-cell expression of RANK ligand in acute coronary syndrome: possible role in plaque destabilization," Arteriosclerosis, Thrombosis, and Vascular Biology, vol. 26, no. 4, pp. 857-863, 2006.

[88] H. Hsu, D. L. Lacey, C. R. Dunstan, et al., "Tumor necrosis factor receptor family member RANK mediates osteoclast differentiation and activation induced by osteoprotegerin ligand," Proceedings of the National Academy of Sciences of the United States of America, vol. 96, no. 7, pp. 3540-3545, 1999.

[89] D. M. Anderson, E. Maraskovsky, W. L. Billingsley, et al., "A homologue of the TNF receptor and its ligand enhance T-cell growth and dendritic-cell function," Nature, vol. 390, no. 6656, pp. 175-179, 1997.

[90] W. J. Boyle, W. S. Simonet, and D. L. Lacey, "Osteoclast differentiation and activation," Nature, vol. 423, no. 6937, pp. 337-342, 2003.

[91] B. A. Mosheimer, N. C. Kaneider, C. Feistritzer, D. H. Sturn, and C. J. Wiedermann, "Expression and function of RANK in human monocyte chemotaxis," Arthritis \& Rheumatism, vol. 50, no. 7, pp. 2309-2316, 2004.

[92] N. Bucay, I. Sarosi, C. R. Dunstan, et al., "Osteoprotegerindeficient mice develop early onset osteoporosis and arterial calcification," Genes and Development, vol. 12, no. 9, pp. 1260-1268, 1998.

[93] H. Min, S. Morony, I. Sarosi, et al., "Osteoprotegerin reverses osteoporosis by inhibiting endosteal osteoclasts and prevents vascular calcification by blocking a process resembling osteoclastogenesis," Journal of Experimental Medicine, vol. 192, no. 4, pp. 463-474, 2000.

[94] J. M. Lin, K. E. Callon, C. Q. Lin, et al., "Alteration of bone cell function by RANKL and OPG in different in vitro models," European Journal of Clinical Investigation, vol. 37, no. 5, pp. 407-415, 2007.

[95] C. R. Dhore, J. P. M. Cleutjens, E. Lutgens, et al., "Differential expression of bone matrix regulatory proteins in human atherosclerotic plaques," Arteriosclerosis, Thrombosis, and Vascular Biology, vol. 21, no. 12, pp. 1998-2003, 2001.

[96] M. Schoppet, N. Al-Fakhri, F. E. Franke, et al., "Localization of osteoprotegerin, tumor necrosis factor-related apoptosisinducing ligand, and receptor activator of nuclear factor- $\kappa \mathrm{B}$ ligand in Mönckeberg's sclerosis and atherosclerosis," Journal of Clinical Endocrinology \& Metabolism, vol. 89, no. 8, pp. 4104-4112, 2004.

[97] A. Dovio, V. Data, and A. Angeli, "Circulating osteoprotegerin and soluble RANKL: do they have a future in clinical practice?" Journal of Endocrinological Investigation, vol. 28, supplement 10, pp. 14-22, 2005.

[98] P. Collin-Osdoby, "Regulation of vascular calcification by osteoclast regulatory factors RANKL and osteoprotegerin," Circulation Research, vol. 95, no. 11, pp. 1046-1057, 2004.

[99] K. E. Watson, M. L. Abrolat, L. L. Malone, et al., "Active serum vitamin D levels are inversely correlated with coronary calcification," Circulation, vol. 96, no. 6, pp. 1755-1760, 1997.
[100] T. M. Doherty, W. Tang, S. Dascalos, et al., "Ethnic origin and serum levels of $1 \alpha, 25$-dihydroxyvitamin D3 are independent predictors of coronary calcium mass measured by electronbeam computed tomography," Circulation, vol. 96, no. 5, pp. 1477-1481, 1997.

[101] Y. Arad, L. A. Spadaro, M. Roth, et al., "Serum concentration of calcium, 1,25 vitamin D and parathyroid hormone are not correlated with coronary calcifications. An electron beam computed tomography study," Coronary Artery Disease, vol. 9, no. 8, pp. 513-518, 1998.

[102] N. K. Wenger, "Coronary heart disease: an older woman's major health risk," British Medical Journal, vol. 315, no. 7115, pp. 1085-1090, 1997.

[103] T. L. Bush, E. Barrett-Connor, L. D. Cowan, et al., "Cardiovascular mortality and noncontraceptive use of estrogen in women: results from the Lipid Research Clinics Program Follow-up Study," Circulation, vol. 75, no. 6, pp. 1102-1109, 1987.

[104] M. E. Mendelsohn and R. H. Karas, "The protective effects of estrogen on the cardiovascular system," The New England Journal of Medicine, vol. 340, no. 23, pp. 1801-1811, 1999.

[105] J. S. Flier, "Physiology: is brain sympathetic to bone?" Nature, vol. 420, no. 6916, pp. 619-622, 2002.

[106] J. M. Blair, H. Zhou, M. J. Seibel, and C. R. Dunstan, "Mechanisms of disease: roles of OPG, RANKL and RANK in the pathophysiology of skeletal metastasis," Nature Clinical Practice Oncology, vol. 3, no. 1, pp. 41-49, 2006.

[107] G. Schett, S. Hayer, J. Zwerina, K. Redlich, and J. S. Smolen, "Mechanisms of disease: the link between RANKL and arthritic bone disease," Nature Clinical Practice Rheumatology, vol. 1, no. 1, pp. 47-54, 2005.

[108] S. Kiechl, P. Werner, M. Knoflach, M. Furtner, J. Willeit, and G. Schett, "The osteoprotegerin/RANK/RANKL system: a bone key to vascular disease," Expert Review of Cardiovascular Therapy, vol. 4, no. 6, pp. 801-811, 2006.

[109] W. S. Browner, L.-Y. Lui, and S. R. Cummings, "Associations of serum osteoprotegerin levels with diabetes, stroke, bone density, fractures, and mortality in elderly women," Journal of Clinical Endocrinology \& Metabolism, vol. 86, no. 2, pp. 631637, 2001.

[110] M. Schoppet, A. M. Sattler, J. R. Schaefer, M. Herzum, B. Maisch, and L. C. Hofbauer, "Increased osteoprotegerin serum levels in men with coronary artery disease," Journal of Clinical Endocrinology \& Metabolism, vol. 88, no. 3, pp. 10241028, 2003.

[111] M. Soufi, M. Schoppet, A. M. Sattler, et al., "Osteoprotegerin gene polymorphisms in men with coronary artery disease," Journal of Clinical Endocrinology \& Metabolism, vol. 89, no. 8, pp. 3764-3768, 2004.

[112] S. Jono, Y. Ikari, A. Shioi, et al., "Serum osteoprotegerin levels are associated with the presence and severity of coronary artery disease," Circulation, vol. 106, no. 10, pp. 1192-1194, 2002.

[113] M. Schoppet, J. R. Schaefer, and L. C. Hofbauer, "Low serum levels of soluble RANK ligand are associated with the presence of coronary artery disease in men," Circulation, vol. 107, no. 11, p. e76, 2003. 


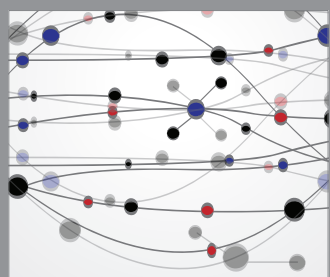

The Scientific World Journal
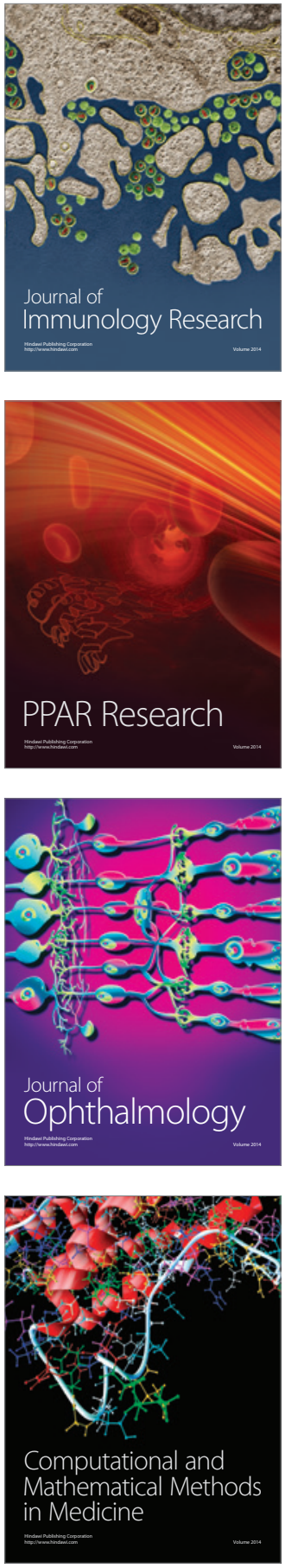

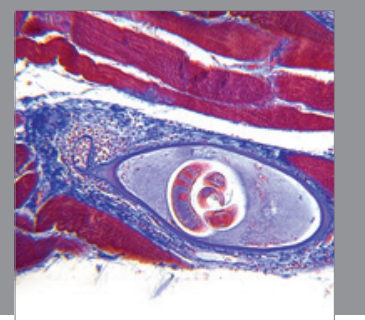

Gastroenterology

Research and Practice
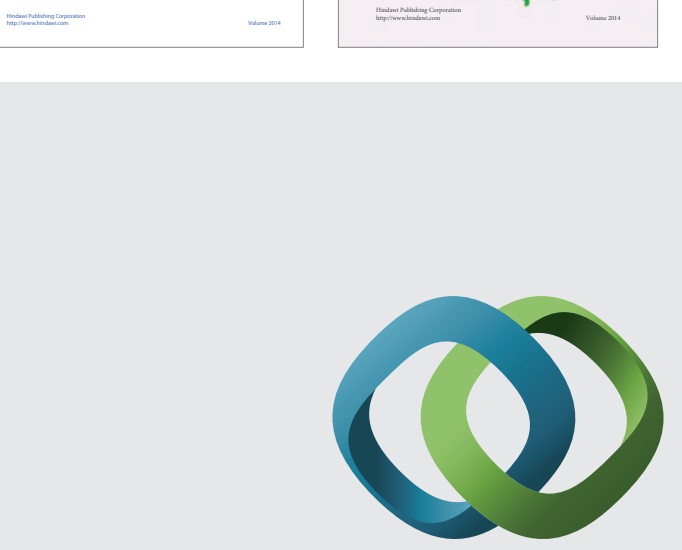

\section{Hindawi}

Submit your manuscripts at

http://www.hindawi.com
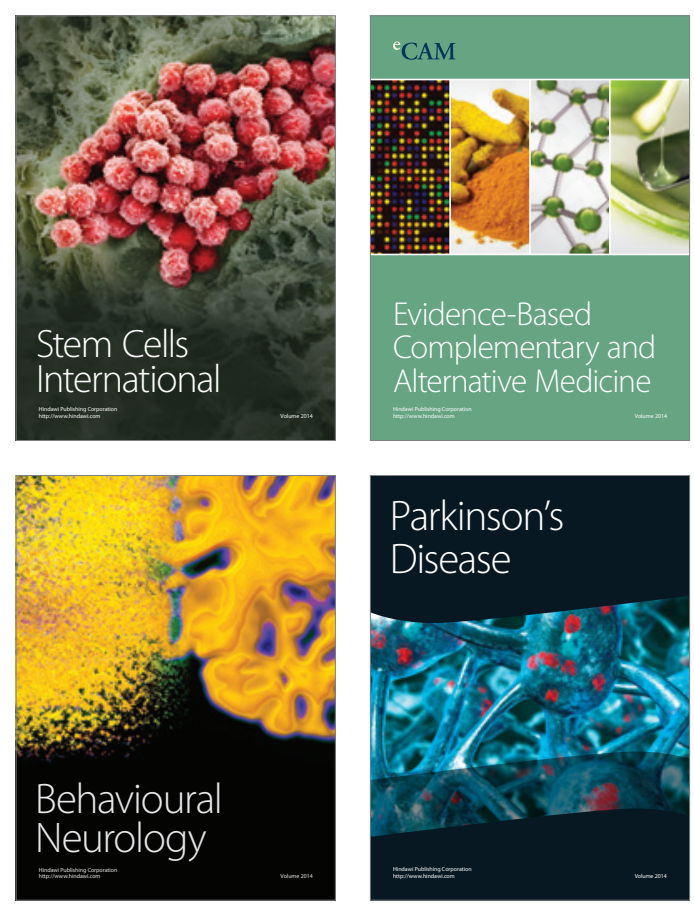

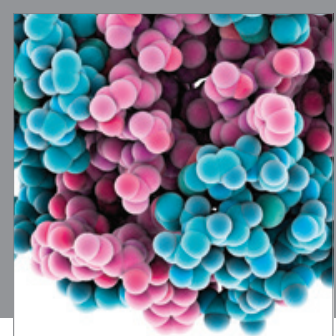

Journal of
Diabetes Research

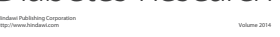

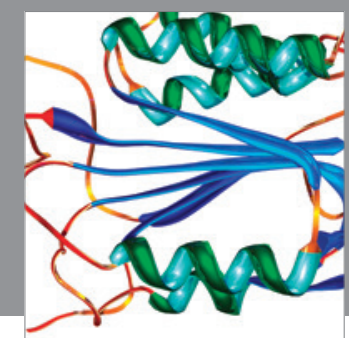

Disease Markers
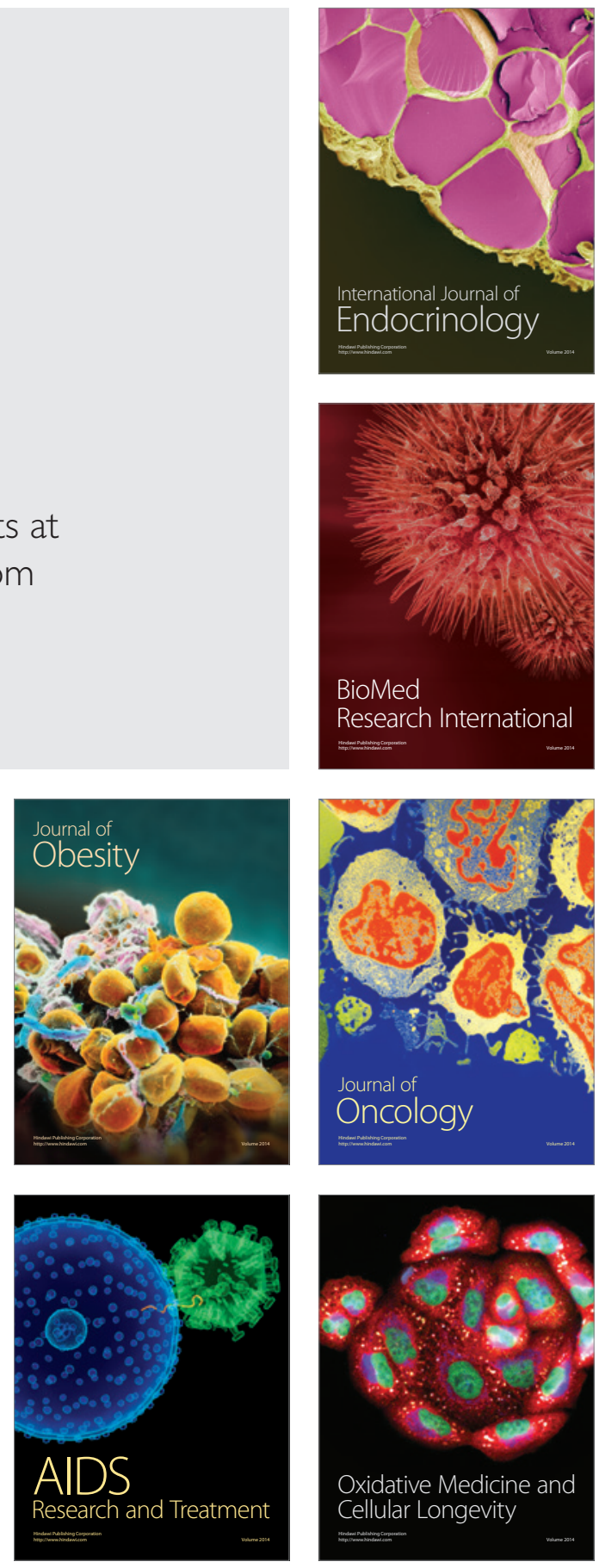